Christina T. Mora MD, ${ }^{*}$ Marc Torjman MEd, $†$ Paul F. White PhD MD FANZCA $\ddagger$

\title{
Sedative and ventilatory effects of midazolam infusion: effect of flumazenil reversal
}

The purpose of this study was to evaluate the effects of flumazenil ( $1 \mathrm{mg} i \mathrm{w}$ ) on the ventilatory response of premedicated patients receiving a continuous infusion of midazolam for sedation. After assessing baseline ventilatory function using $a$ modified Read rebreathing method for determining hypercapnic ventilatory drive, 16 healthy outpatients were administered fentanyl, $50 \mu \mathrm{g} \dot{\mathrm{N}}$, and midazolam $2 \mathrm{mg} \dot{\mathrm{N}}$, followed by a variable-rate midazolam infusion, $0.3-0.5 \mathrm{mg} \cdot \mathrm{min}^{-1}$. Upon termination of the midazolam infusion, serum midazolam concentrations were measured and ventilatory function was reassessed. Then, $10 \mathrm{ml}$ of either saline or flumazenil $(1 \mathrm{mg}$ ) were administered according to a randomized, double-blind protocol. Ventilatory function was subsequently measured at $5 \mathrm{~min}, 30$ min and 60 min intervals after study drug. Compared with the baseline value, midazolam infusion reduced tidal volume and increased respiratory rate and alveolar dead space. However, midazolam did not decrease the slope of the $\mathrm{CO}_{2}$ response curve. Flumazenil reduced the degree of midazolam-induced sedation and the decrease in tidal volume $(P<0.05)$, but not the change in resting respiratory rate. In some patients, the

\section{Key words}

ANAESTHETIC TECHNIQUES: intravenous; infusion;

ANALGESICS: fentanyl;

ANTAGONISTS: benzodiazepines; flumazenil;

HYPNOTICS: benzodiazepines; midazolam; MEASUREMENT TECHNIQUES: $\mathrm{CO}_{2}$ response curve.

From the Departments of Anesthesiology at *Emory University School of Medicine, Atlanta, Georgia 30322, and, †Jefferson Medical College of Thomas Jefferson University, Philadelphia, PA 19107, and, ¥University of Texas

Southwestern Medical Center, Dallas, TX 75235.

This study was supported in part by a research grant from the Ambulatory Anesthesia Research Foundation, Dallas, TX.

Address correspondence to: Dr. Paul F. White, Department of Anesthesiology and Pain Management, University of Texas Southwestern Medical Center, 5323 Harry Hines Boulevard, Dallas, Texas 75235-9068.

Accepted for publication 14th April, 1995. ventilatory response to hypercarbia actually decreased after flumazenil administration compared with the immediate prereversal (sedated) values. It is concluded that midazolam infusion, $0.43 \mathrm{mg} \cdot \mathrm{min}^{-1}$, did not impair $\mathrm{CO}_{2}$-responsiveness. Flumazenil's effect on central ventilatory drive was more variable than its reversal of midazolam-induced sedation.

Cette étude vise à évaluer les effets du flumazénil (l mg iv) sur la réponse ventilatoire de patients prémédiqués qui reçoivent, pour fin de sédation, une perfusion continue de midazolam. Après avoir établi la ventilation initiale avec une méthode de réinspiration de Read modifiée, dans le but de déterminer l'effort ventilatoire hypercapnique, 16 patients ambulatoires bien portants reçoivent fentanyl $50 \mu \mathrm{g} i \mathrm{v}$ et midazolam $2 \mathrm{mg}$ iv suivis diune perfusion de midazolam à débit variable à la vitesse de $0,3-0,5 \mathrm{mg} \cdot \mathrm{min}^{-1}$. Une fois la perfusion terminée, les concentrations sériques de midazolam sont mesurées et la ventilation réévaluée. Par la suite, une solution de $10 \mathrm{ml}$ contenant soit du soluté physiologique soit du flumazénil ( $1 \mathrm{mg}$ ) est administrée aléatoirement et à double aveugle. La ventilation est par la suite mesurée à des intervalles de $5 \mathrm{~min}, 30 \mathrm{~min}$ et $60 \mathrm{~min}$. Comparativement aux valeurs de base, la perfusion de midazolam diminue le volume minute et augmente la fréquence respiratoire et l'espace mort alvéolaire. Cependant, le midazolam ne modifie pas la pente de la courbe de réponse au $\mathrm{CO}_{2}$. Le flumazénil diminue le niveau de sédation induit par le midazolam et la baisse du volume courant $(P<0,05)$, mais non le changement de la fréquence respiratoire. Chez certains patients, la réponse ventilatoire à lhypercarbie diminue après l'administration de flumazénil comparativement aux valeurs qui précèdent immédiatement l'antagonisme. En conclusion, une perfusion de midazolam $0,43 \mathrm{mg} \cdot \mathrm{min}^{-1} \mathrm{n}$ 'altère pas la réactivité au $\mathrm{CO}_{2}$. L'effet du flumazénil sur l'effort respiratoire central est plus variable que sa capacité de renverser la sédation induite par le midazolam.

Benzodiazepines and opioid analgesics are widely used for producing sedation and analgesia during monitored anaesthesia care. Large bolus doses of midazolam can 
produce large decreases in both ventilatory drive and haemoglobin oxygen saturation, ${ }^{1}$ in particular when combined with potent opioid analgesics. ${ }^{23}$ However, there are conflicting data in the literature regarding the respiratory effects of sedative doses of benzodiazepines. ${ }^{4-9}$ Although most patients experience varying degrees of ventilatory depression following administration of intravenous bolus doses of benzodiazepines, some patients may display enhanced respiratory drive. ${ }^{5}$ The effect of a continuous intravenous infusion of midazolam on the ventilatory response to hypercarbia has not been previously reported.

Flumazenil, a centrally-active imidazobenzodiazepine, antagonizes the sedative, amnestic and electroencephalographic depressant effects of midazolam and diazepam. ${ }^{10-12}$ Flumazenil appears to be devoid of any intrinsic sedative or respiratory depressant effects, even after large supra-therapeutic doses. ${ }^{13}$ However, the effect of flumazenil on respiratory drive after administration of a benzodiazepine agonist is highly controversial. ${ }^{8,14-18}$ In a recent publication, Flögel et al. ${ }^{18}$ reported that flumazenil $1 \mathrm{mg}$ $\dot{w}$ was sufficient "to achieve full reversal of midazolam's effects on hypnosis and ventilation." Of interest, these investigators found differences between the duration of flumazenil's reversal of midazolam-induced hypnosis and ventilatory depression.

Therefore, we designed a clinical study to: (1) assess the ventilatory effects of midazolam when administered as a continuous infusion for sedation during outpatient diagnostic procedures, and (2) determine the effects of flumazenil on the level of sedation and respiratory function following midazolam-induced sedation.

\section{Methods}

After obtaining Institutional Review Board approval, we studied 16 healthy, consenting adult outpatients scheduled to undergo diagnostic procedures (e.g., colonoscopy) requiring intravenous sedation. The patients' ages ranged from 30 to $58 \mathrm{yr}$, with a mean ( \pm SD) of $42.5 \pm 8 \mathrm{yr}$. Patients who were obese, had a history of pulmonary disease, chronically used benzodiazepines or other centrally active drugs, or had a history of alcohol or drug abuse, were excluded. All patients were fasted for at least eight hours before entry into the study.

\section{Experimental procedure}

Before undergoing their diagnostic procedure, the patients were familiarized with the study protocol and baseline measurements of ventilatory function (respiratory rate $(\mathrm{RR})$, tidal volume $(\mathrm{VT})$, minute ventilation $(\mathrm{VE})$, endtidal carbon dioxide $\left(\mathrm{PETCO}_{2}\right)$, and the slope of the ventilatory response to carbon dioxide) were obtained using the Read rebreathing method. ${ }^{19}$ Arterial oxygen saturation $\left(\mathrm{SpO}_{2}\right)$ was measured using finger pulse oximetry.
Each patient assessed their level of sedation by placing a mark on a $100 \mathrm{~mm}$ visual analogue scale $(0=$ awake $/$ alert to $100=$ unresponsive/sleeping). Sedation was also assessed by a trained observer using a five-point scale ( 1 = alert, $2=$ sleepy, $3=$ responsive to verbal stimuli, $4=$ responsive to light tactile stimulation, $5=$ asleep and difficult to arouse).

Patients were transferred to the endoscopy suite and two $18 \mathrm{ga}$ indwelling intravenous (iv) catheters were placed in contralateral upper extremities for administration of $\dot{w}$ fluids (5\% dextrose in lactated Ringer's solution) and the study medications, and the second catheter was used to obtain blood samples for determination of serum midazolam concentration. After placing routine monitors (ECG, blood pressure cuff and finger pulse oximeter), patients were premedicated with fentanyl, $50 \mu \mathrm{g} \dot{\mathrm{N}}$, and sedation was intiated with a loading dose of midazolam, $2 \mathrm{mg}, i v$. Sedation was subsequently maintained with a variable-rate midazolam infusion, $0.3-0.5 \mathrm{mg} \cdot \mathrm{min}^{-1} \dot{w}$. Patients were breathing room air throughout the study period. The midazolam infusion rate was varied to maintain a stable level of sedation at which the patients were resting comfortably with their eyes closed, but responded to light tactile stimulation (level 3-4 on the five-point sedation scale). Upon completion of the diagnostic procedure, the degree of sedation, ventilatory drive, and respiratory variables were reassessed and the midazolam infusion was discontinued. Plasma midazolam concentration was measured, using a standard gas chromatography-mass spectrometry analytical technique, ${ }^{20}$ at the end of the procedure and upon completion of the end-infusion ventilatory study. The average midazolam concentration for the two determinations was correlated with the changes in ventilatory function.

After completing the above assessments, $10 \mathrm{ml}$ of either flumazenil, $1.0 \mathrm{mg}$ (flumazenil group, $n=9$ ) or normal saline (control group, $n=7$ ) were administered $i v$ in a randomized, double-blind fashion. The level of sedation, slope of the $\mathrm{CO}_{2}$-response curve, respiratory variables and $\mathrm{SpO}_{2}$ values were reassessed at $5-\mathrm{min}, 30-\mathrm{min}$, and 60-min intervals after administration of the study medication.

\section{Respiratory equipment}

The instrumentation used for this study has been previously described ${ }^{21}$ and consisted of a Medical Graphics System 2001 Lab (Medical Graphics Corporation 350 Oak Grove Parkway, St. Paul MN 55110) modified for a Read rebreathing system with minimal dead space (110 $\mathrm{ml})$. The breathing circuit was filled with $7 \% \mathrm{CO}_{2}$ and the balance consisted of oxygen. The total system resistance was $0.5 \mathrm{~cm} \mathrm{H}_{2} \mathrm{O}$ at a flow of $1 \mathrm{~L} \cdot \mathrm{sec}^{-1}$. The ambient conditions were stable and instrument calibra- 
tion corrections were applied to correct for any changes in temperature or humidity prior to each test. The endtidal gases were measured with rapid response $\mathrm{O}_{2}$ and $\mathrm{CO}_{2}$ analyzers requiring $150 \mathrm{ml}$ gas samples per minute. The analyzer's response time at the sensor was less than 100 msec. Each analyzer was calibrated with certified gas to be accurate to $0.03 \%$. Flow was measured with a heated linear pneumotachograph (Hans Rudolph Model 3813, Hans Rudolph, Inc., Kansas City, MO), with a linear flow range from 0 to $800 \mathrm{~L} \cdot \mathrm{min}^{-1}$.

Using on-line breath-by-breath waveform analysis, the instrument permitted close observation of VE, PETCO end-tidal $\mathrm{O}_{2}, \mathrm{VT}$, and $\mathrm{RR}$. Respiratory variables for any given breath could be examined on the CRT screen using the replay mode software.

\section{Measurement of ventilatory drive}

During all ventilatory drive studies, subjects were seated in an upright position with the torso at approximately $100^{\circ}$ to the legs. The mouthpiece was positioned in the patient's mouth and the nose was sealed with a nose clip. The testing conditions were standardized with respect to room lighting and background noise. After determining that the patient was comfortable with stable $V E$ and $\mathrm{PETCO}_{2}$ values and that no leaks were present in the breathing circuit, the data collection process was started. Under normal conditions, four to five minutes of breathing room air were sufficient to reach stable values of $\mathrm{VE}$ and $\mathrm{PETCO}_{2}$. Carbon dioxide rebreathing was started by turning the three-way valve to the "rebreathing" position. The test was terminated after approximately four minutes when a $\mathrm{PETCO}_{2}$ of $60 \mathrm{mmHg}$ was reached.

\section{Calculation of respiratory variables}

The $\mathrm{CO}_{2}$ response studies were immediately replayed on the CRT screen using an X-Y graph. Approximately 40 to 70 data points were obtained during each study for the regression analysis. Swallows or coughs were rejected by the computer which recognized incomplete breathing cycles. The ventilatory slope was calculated using a regression analysis over the linear portion of the ventilation vs PEICO ${ }_{2}$ curve. We assessed the displacement of the $\mathrm{CO}_{2}$ response curve by determining the magnitude of the shift in the $\mathrm{CO}_{2}$ response "threshold" value, defined as the $\operatorname{PETCO}_{2}$ at which $\mathrm{VE}$ changes linearly with further increases in carbon dioxide. ${ }^{21}$ In order to assess drug effects on VT and RR, the "resting" variables were measured at the same $V E$ for all subjects and at a $V E$ of $20 \mathrm{~L} \cdot \mathrm{min}^{-1}$ during the rebreathing period (approximately mid-phase of the $\mathrm{CO}_{2}$ response determinations).

Changes in the physiological (respiratory) dead space were quantified using the Bohr-Engoff equation where
$\mathrm{PaCO}_{2}$ was estimated from $\mathrm{PETCO}_{2}$ using the method of Jones and Campbell: ${ }^{22}$

$$
\begin{aligned}
& \text { Estimated } \begin{array}{r}
\mathrm{PaCO}_{2}\left(\mathrm{EPaCO}_{2}\right) \\
=5.5+0.9 \mathrm{PETCO}_{2}-0.0021 \mathrm{VT}
\end{array} \\
& \mathrm{VD}=\frac{\mathrm{EPaCO}_{2}-\mathrm{PETCO}_{2}}{\mathrm{EPaCO}_{2}} \text { (VT-valve dead space). }
\end{aligned}
$$

Data were subjected to univariate and multivariate analysis of variance (ANOVA), with intra- and intergroup changes over time assessed using repeated measures of ANOVA. Inspection of differences between mean values was performed using the protected least significant difference test. Finally, nominal data were analyzed using the Kruskal Wallis and sign tests. A $P$-value $<0.05$ was considered statistically significant.

\section{Results}

The 16 study patients received a total midazolam dose of $27.6 \pm 13.1 \mathrm{mg} i v$ (mean $\pm \mathrm{SD}$ ), infused over 63 \pm 23 min (Table I). The mean ( \pm SD) plasma midazolam concentration at the time the end-infusion (sedated) respiratory testing was performed was $364 \pm 310$ $\mathrm{ng} \cdot \mathrm{ml}^{-1}$. As expected, end-infusion sedation assessment scores (determined by a trained observer) and visual analogue scale scores (assessed by the patient), were higher than the preoperative baseline values. In all patients, baseline and end-infusion respiratory measurements were within the normal range for healthy subjects (Table II).

With the exception of one subject who was prone during the procedure, all patients were positioned in the lateral decubitus position. The prone patient transiently desaturated from an $\mathrm{SpO}_{2}$ value of $98 \%$ to $89 \%$, and one patient who was in the lateral decubitus position experienced a decrease in $\mathrm{SpO}_{2}$ from $98 \%$ to $92 \%$. There was an increase in the respiratory rate and the resting PETCO$_{2}$, and a decrease in VT at the end of the midazolam infusion $(P>0.01)$. The slope of the curve relating ventilatory response to $\mathrm{PETCO}_{2}$ was not different from the baseline value at the end-infusion measurement. However, there was an increase in the $\mathrm{CO}_{2}$ response curve threshold value from $48 \pm 3$ (baseline) to $51 \pm 2 \mathrm{mmHg}$ following midazolam sedation.

In comparing the VT values when the subjects were breathing at rest (resting VE pre-rebreathing) and at a $\mathrm{VE}$ of $20 \mathrm{~L} \cdot \mathrm{min}^{-1}(\mathrm{VT} 20)$, we found decreases from presedation (baseline) values at the end-infusion testing interval. The decreases in VT values were accompanied by concomitant increases in the RR. Respiratory dead space $\left(V_{D} / V_{T}\right)$ also increased with midazolam sedation. There was no correlation between plasma midazolam concentration and the changes from baseline to post-sedated (end-infusion) values for either $\mathrm{PETCO}_{2}$ values or the 
TABLE I Patient demographic data, duration of sedation, drug doses, and plasma midazolam levels*

\begin{tabular}{|c|c|c|c|}
\hline & $\begin{array}{l}\text { All } \\
\text { patients }\end{array}$ & $\begin{array}{l}\text { Saline } \\
\text { group }\end{array}$ & $\begin{array}{l}\text { Flumazenil } \\
\text { group }\end{array}$ \\
\hline Number $(n)$ & 16 & 7 & 9 \\
\hline $\operatorname{Sex}(M / F)$ & $10 / 6$ & $4 / 3$ & $6 / 3$ \\
\hline Age (yr) & $42.5 \pm 8$ & $43 \pm 5$ & $42 \pm 15$ \\
\hline Weight (kg) & $70 \pm 11.5$ & $71 \pm 15$ & $69 \pm 9$ \\
\hline ASA physical status I/II & $14 / 2$ & $7 / 0$ & $7 / 2$ \\
\hline Midazolam dosage (mg) & $27.6 \pm 13.1$ & $27 \pm 9$ & $28 \pm 16$ \\
\hline Duration of sedation (min) & $63.5 \pm 22.7$ & $69 \pm 32$ & $59 \pm 14$ \\
\hline $\begin{array}{l}\text { Midazolam infusion rate } \\
\left(\mathrm{mg} \cdot \mathrm{min}^{-1}\right)\end{array}$ & $0.4 \pm 0.16$ & $0.4 \pm 0.1$ & $0.4 \pm 0.2$ \\
\hline $\begin{array}{l}\text { Midazolam concentration } \\
\left(\mathrm{ng} \cdot \mathrm{ml}^{-1}\right)\end{array}$ & $364 \pm 310$ & $372 \pm 371$ & $358 \pm 277$ \\
\hline
\end{tabular}

*Data expressed as mean values \pm SD.

TABLE II Preoperative (baseline) and end-infusion sedation and respiratory variables (mean $\pm S D$ )

\begin{tabular}{|c|c|c|}
\hline & Baseline & End-infusion \\
\hline Sedation score (1-5) & 1.0 & $3.6 \pm 0.6^{*}$ \\
\hline VAS sedation scale (mm) & $14 \pm 14$ & $96 \pm 8^{*}$ \\
\hline Resting end-tidal $\mathrm{CO}_{2}(\mathrm{mmHg})$ & $38.5 \pm .2 .7$ & $41.6 \pm 1.9 \dagger$ \\
\hline Resting VE $\left(\mathbf{L} \cdot \mathrm{min}^{-1}\right)$ & $9.5 \pm 1.6$ & $9.6 \pm 1.5$ \\
\hline $\mathrm{CO}_{2}$ response $\left(\mathrm{VE} / \mathrm{PETCO}_{2}\right)$ & $2.7 \pm 1.3$ & $3.0 \pm 1.3$ \\
\hline $\mathrm{CO}_{2}$ threshold (mmHg) & $48 \pm 3$ & $51 \pm 2 \dagger$ \\
\hline VT at resting VE (m) & $751 \pm 153$ & $502 \pm 86 \dagger$ \\
\hline$R R$ at resting $V E(b p m)$ & $13 \pm 4$ & $20 \pm 5+$ \\
\hline Resting VD/VT ratio & $0.38 \pm 0.07$ & $0.48 \pm 0.09 \dagger$ \\
\hline $\mathrm{VT}$ at $\mathrm{VE}=20 \mathrm{~L} \cdot \mathrm{min}^{-1}(\mathrm{ml})$ & $1333 \pm 340$ & $996 \pm 207 \dagger$ \\
\hline$R R$ at $V_{E}=20 \mathrm{~L} \cdot \min ^{-1}(\mathrm{bpm})$ & $16 \pm 4$ & $21 \pm 5^{*}$ \\
\hline Resting arterial $\mathrm{O}_{2}$ saturation (\%) & $97 \pm 2$ & $96 \pm 2$ \\
\hline
\end{tabular}

$* P<0.05$ from baseline values.

$+P<0.01$ from baseline values.

slopes of the ventilatory response curves (data not reported).

In the second phase of the study, the patients were randomly assigned to either a control (saline) or flumazenil treatment group. There were no differences noted with respect to demographic data (Table I). The slopes of the pre-treatment (end-infusion) ventilatory response curves and respiratory variables (VT, RR, $V_{D} / V_{T}$, $\mathrm{PETCO}_{2}$ ) did not differ between the two groups. Following the administration of the study drug (saline or flumazenil), the flumazenil-treated patients had lower sedation scores as measured by both the visual analogue scale and the observer's sedation assessment score (Figure 1). In comparing the ventilatory drive measurements performed before and after saline administration with baseline values, we found no changes in the calculated $\mathrm{CO}_{2}$ response curves at any of the time intervals studied (Figure 2). The respiratory response to hypercarbia after flu-

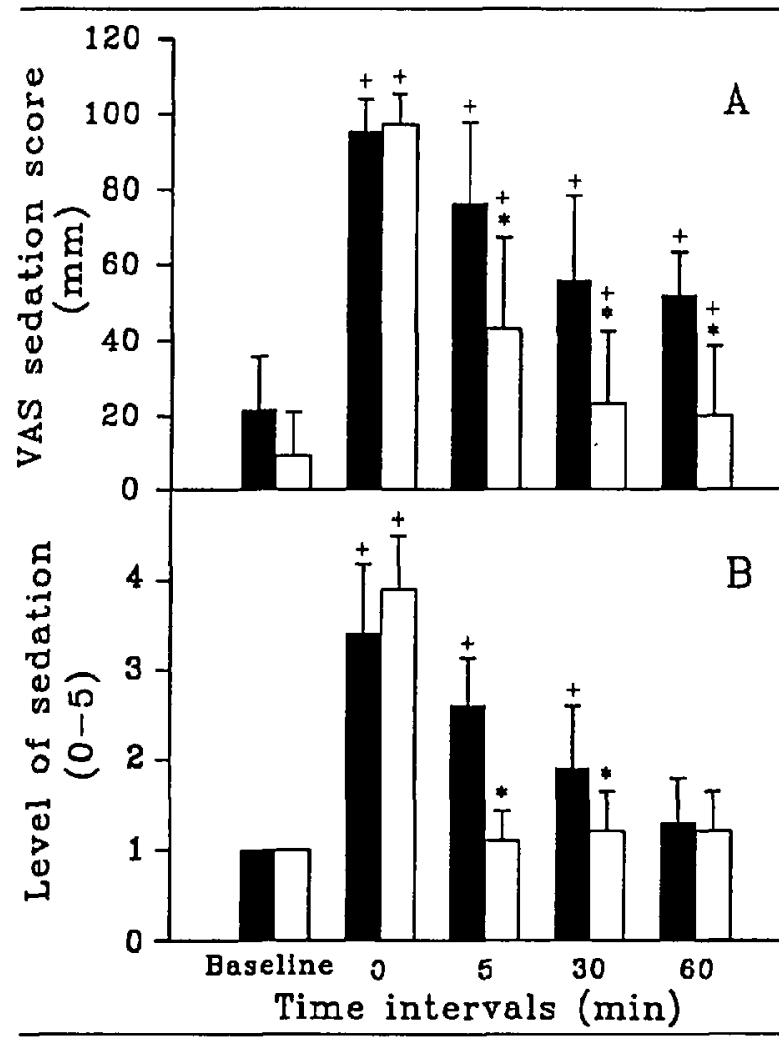

FIGURE 1 (A) Sedation visual analogue scale (VAS) scores before (sedated) and after study drug administration, (B) Observer sedation assessment scores before and after study drug administration. $\square=$ saline, $\square=$ flumazenil $1 \mathrm{mg},{ }^{*} P<0.05$ versus saline, $+P<0.01$ versus baseline.

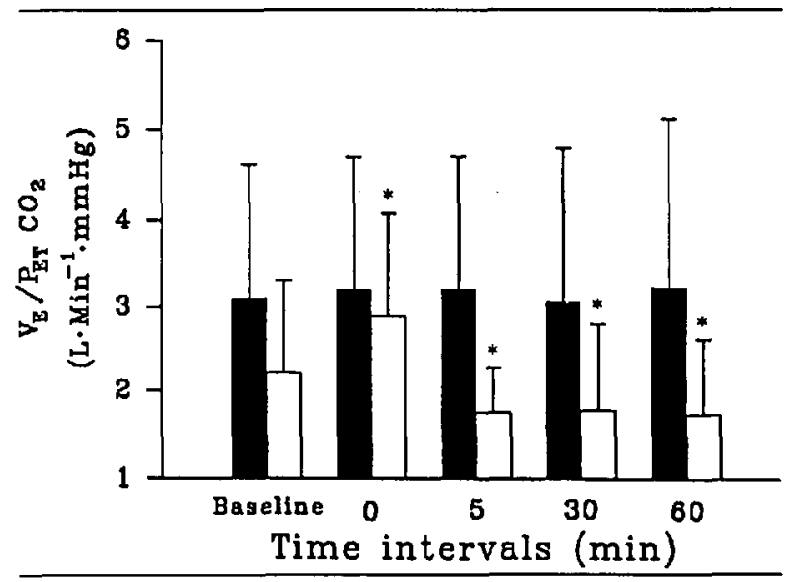

FIGURE 2 The slope of the $\mathrm{CO}_{2}$ response curve $\left(\mathrm{VE} / \mathrm{PETCO}_{2}\right)$ preoperatively (baseline), end-infusion (time 0 ) and at 5-min, 30-min, and 60-min intervals after either saline (D) or flumazenil $1 \mathrm{mg}(\square)$.

mazenil administration was decreased compared with the end-infusion measurements; however, the post-flumazenil values were not different from the pre-sedation "baseline" values $(P=0.06)$. In the saline group, the $\mathrm{CO}_{2}$ threshold values were elevated above the baseline value at all sub- 


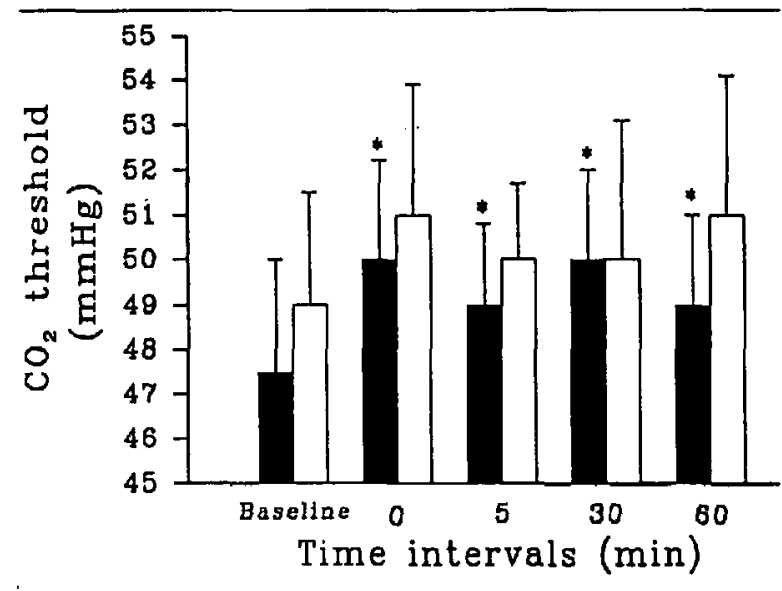

FIGURE 3 The $\mathrm{CO}_{2}$ threshold values (at which VE increases linearly with end-tidal $\mathrm{CO}_{2}$ ) preoperatively (baseline), at the end of the midazolam infusion (time 0 ) and at 5-min, 30-min, and 60-min intervals after either saline ( $\square$ ) or flumazenil $1 \mathrm{mg}(\square),{ }^{*} P<0.01$ versus baseline.

sequent time intervals $(P<0.01)$. Flumazenil produced no changes in $\mathrm{CO}_{2}$ threshold values compared with the end-infusion measurements (Figure 3).

Changes in RR and VT measured at rest and at $V_{E}$ $=20 \mathrm{~L} \cdot \min ^{-1}$ while the subject was awake (baseline), sedated, and at 5-min, 30-min, and 60-min intervals after the administration of either saline or flumazenil are summarized in Table III. Following midazolam sedation, RR increased and $V_{T}$ decreased at resting $V E$ and when $V E$ equaled $20 \mathrm{~L} \cdot \mathrm{min}^{-1}$ in both the saline and flumazenil treatment groups. In both groups, RR, resting $V_{T}$ and VT20 values returned toward baseline values at the subsequent testing intervals. More importantly, no differences were found between the flumazenil and saline treatment groups with respect to resting $\mathrm{VT}_{\mathrm{T}}$ and $\mathrm{V}_{\mathrm{T}} 20$ values at $30 \mathrm{~min}$ and $60 \mathrm{~min}$ after study drug administration. Finally, the study drugs had no effects on alveolar ventilation as assessed by $\mathrm{VD} / \mathrm{VT}$ ratios (Figure 4).

\section{Discussion}

While large bolus doses of midazolam $\left(0.15 \mathrm{mg} \cdot \mathrm{kg}^{-1}\right.$ $i v)$ have been associated with clinically important respiratory depression, ' smaller doses $\left(0.04-0.08 \mathrm{mg} \cdot \mathrm{kg}^{-1} \dot{w}\right)$ have minimal effect on respiratory drive. ${ }^{2,4}$ Despite increases in both subjective and objective sedation scores (Table II), our data suggest that the use of a variablerate midazolam infusion, at a mean rate of 0.43 $\mathrm{mg} \cdot \mathrm{min}^{-1}$, did not decrease central ventilatory drive in response to a hypercapnic challenge. These data are consistent with the recent findings of Mak et al. ${ }^{77}$ following oral midazolam. Although it was not evaluated in our study, depression of hypoxic drive may be a more important clinical problem with large doses of midazolam. ${ }^{7,8}$
As reported previously following intermittent bolus doses of midazolam, ${ }^{6}$ we found that midazolam infusion produced a decrease in VT, as well as a concomitant increase in both RR and respiratory dead space. Not surprisingly, an increase in resting $\mathrm{PETCO}_{2}$ was noted at the end of the midazolam infusion. Although the RR remained above the baseline values after flumazenil $1 \mathrm{mg}$ $\dot{i}$, the $\mathrm{VT}$ increased towards the baseline values during the rebreathing period. However, the resting VT values remained below baseline values following flumazenil administration. Barakat et al.* also reported that flumazenil was only partially effective in antagonizing midazolaminduced changes in ventilatory variables, and Flogel $e t$ al. ${ }^{18}$ found that the reduction in the ventilation intercept at a $\mathrm{PETCO}_{2}$ of $58 \mathrm{mmHg}$ was not consistently reversed by flumazenil.

The midazolam plasma concentrations measured at the end of the infusion were higher than the levels previously reported to produce hypnosis (or unconsciousness). ${ }^{23} \mathrm{Al}$ though these patients were very somnolent at the endinfusion assessment interval, they were easily arousable and were able to cooperate for the respiratory measurements performed prior to and five minutes after administration of the study drugs. These data suggest that tolerance to both the sedative and respiratory depressant effects of midazolam may have developed during the infusion period. Of interest, Berggren et al. ${ }^{6}$ also reported that despite increased plasma concentrations of midazolam, subsequent bolus doses of midazolam ( 0.05 $\mathrm{mg} \cdot \mathrm{kg}^{-1}$ ) did not cause further changes in ventilatory variables. Analogous to the findings of Berggren et al., ${ }^{6}$ we found no correlation between the plasma midazolam concentrations and changes in the resting $\mathrm{PETCO}_{2}$ values or slopes of the $\mathrm{CO}_{2}$-response curves (data not reported). Similarly, Sunzel $e t$ al. ${ }^{24}$ found no correlation between the plasma concentration of midazolam and changes in any of the respiratory variables.

Given the inherent complexity of the mechanisms involved in the control of breathing and the small group sizes, it is not surprising that we were unable to find a correlation between plasma midazolam concentrations and respiratory variables. A further confounding factor may have been the small dose of fentanyl $(50 \mu \mathrm{g} i)$ administered prior to induction of midazolam sedation. While a sedative dose of midazolam $\left(0.05 \mathrm{mg} \cdot \mathrm{kg}^{-1} i \mathrm{v}\right)$ produced no respiratory effects when administered to healthy volunteers, ${ }^{2}$ the combination of midazolam and fentanyl increased the incidence of both hypoxemia and

*Barakat T, Lechat JP, Laurent P, Fletcher D, Clergue F, Viars $P$. Ventilatory effects of flumazenil on midazolaminduced sedation. Anesthesiology 1988; 69: A817. 
TABLE III Respiratory variables at rest (pre-rebreathing) and at a VE equal to $20 \mathrm{~L} \cdot \mathrm{min}^{-1}$ in the saline and flumazenil treatment groups. Data are presented as mean values $\pm S D$

A. Changes in respiratory rate (bpm) at rest and at $\mathrm{VE}=20 \mathrm{~L} \cdot \mathrm{min}^{-1}$

\begin{tabular}{|c|c|c|c|c|}
\hline & \multicolumn{2}{|c|}{ Resting $R R$} & \multicolumn{2}{|c|}{$R R$ at $V E=20 \mathrm{~L} \cdot \mathrm{min}^{-1}$} \\
\hline & Saline & Flumazenil & Saline & Flumazenil \\
\hline $\begin{array}{l}\text { Baseline } \\
\text { (preoperative) }\end{array}$ & $13 \pm 4$ & $13 \pm 4$ & $16 \pm 6$ & $16 \pm 2$ \\
\hline $\begin{array}{l}\text { Sedated } \\
\text { (end-infusion) }\end{array}$ & $20 \pm 4^{*}$ & $19 \pm 4^{*}$ & $20 \pm 4^{*}$ & $22 \pm 5^{*}$ \\
\hline 5 min post-reversal & $16 \pm 4^{*} \dagger$ & $16 \pm 5^{*}$ & $19 \pm 5^{*}$ & $17 \pm 5 \dagger$ \\
\hline 30 min post-reversal & $16 \pm 5^{*+}$ & $17 \pm 6^{*}$ & $17 \pm 7 \dagger$ & $19 \pm 6^{*}$ \\
\hline $60 \mathrm{~min}$ post-reversal & $16 \pm 5^{*+}$ & $17 \pm 5^{*}$ & $17 \pm 5 \dagger$ & $19 \pm 5^{*}$ \\
\hline
\end{tabular}

B. Changes in tidal volume (ml) measured at rest and at $\mathrm{VE}=20 \mathrm{~L} \cdot \mathrm{min}^{-1}$

\begin{tabular}{|c|c|c|c|c|}
\hline & \multicolumn{2}{|l|}{ Resting $V T$} & \multicolumn{2}{|l|}{$V T 20$} \\
\hline & Saline & Fhumazenil & Saline & Flumazenil \\
\hline $\begin{array}{l}\text { Baseline } \\
\text { (preoperative) }\end{array}$ & $794 \pm 194$ & $714 \pm 104$ & $1444 \pm 461$ & $1237 \pm 161$ \\
\hline $\begin{array}{l}\text { Sedated } \\
\text { (end-infusion) }\end{array}$ & $516 \pm 77^{*}$ & $489 \pm 97^{*}$ & $1026 \pm 173^{*}$ & $970 \pm 244^{*}$ \\
\hline $5 \mathrm{~min}$ post-reversal & $611 \pm 159^{*}$ & $600 \pm 102 * \dagger$ & $1106 \pm 245^{*}$ & $1234 \pm 288 \dagger$ \\
\hline $30 \mathrm{~min}$ post-reversal & $694 \pm 172 \dagger$ & $562 \pm 99^{*} \dagger$ & $1315 \pm 388 \dagger$ & $1128 \pm 235 \dagger$ \\
\hline $60 \mathrm{~min}$ post-reversal & $701 \pm 187 \dagger$ & $555 \pm 49^{* \dagger}$ & $1278 \pm 333 \uparrow$ & $1116 \pm 218 \dagger$ \\
\hline
\end{tabular}

$* P<0.05$ versus baseline value.

$+P<0.05$ versus sedated value.

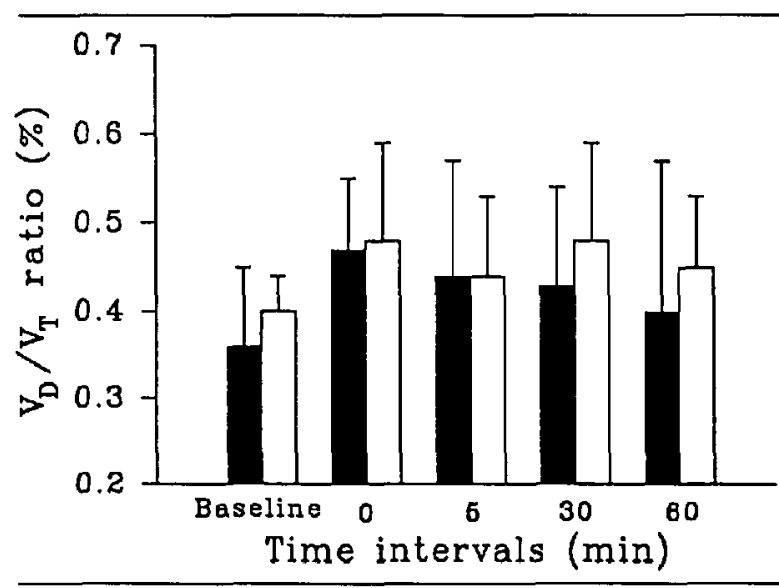

FIGURE 4 The VD/VT ratios during the preoperative (baseline) and at the end of the midazolam infusion (time 0 ) and at 5-min, 30-min, and 60 -min intervals after either saline $(\square)$ or flumazenil $1 \mathrm{mg}(\square)$, ${ }^{*} P<0.01$ versus baseline.

apnoea. Yet, the combination of midazolam and fentanyl did not further increase the depression of the ventilatory response to $\mathrm{CO}_{2}$ produced by fentanyl alone. Of interest, Tolksdorf et al. ${ }^{25}$ reported that considerably more epi- sodes of hypoxaemia were observed when general anaesthesia with midazolam was reversed with flumazenil. These data suggested that flumazenil reversal of benzodiazepine-induced sedation might "unmask" underlying opioid-induced respiratory depression. Weinbrum and Geller ${ }^{26}$ also reported that flumazenil was unable to reverse ventilatory depression in patients who had received both midazolam and an opioid analgesic. Thus, the depression in ventilatory drive noted in some of our patients following flumazenil reversal may have represented the residual effect of the fentanyl premedication.

Consisent with other reports in the literature, ${ }^{10-12,17,18}$ we found that flumazenil, $1 \mathrm{mg} i$, was highly effective in reversing residual midazolam-induced sedation without reversing all the ventilatory effects of midazolam. The explanation for the apparent dissociation between the sedative and respiratory effects after midazolam infusion and flumazenil reversal may be related to the complex interrelationships between neurotransmitters and receptors within the central nervous system (CNS). Since drug effects on both benzodiazepine and GABA receptors appear to influence central respiratory drive, ${ }^{27}$ the dissociation between the sedative and respiratory effects of midazolam 
and flumazenil may be related to differing drug effects on these two receptor populations. In contrast to an intermittent bolus dosing technique, the use of a continuous midazolam infusion would be associated with a slower rate of increase in the plasma (and effect site) concentration of midazolam, as well as lower peak tissue levels. The presence of high plasma midazolam concentrations during the infusion period $(>300) \mathrm{ng} \cdot \mathrm{ml}^{-1}$ ) can also induce changes in CNS benzodiazepine receptor density and affinity. ${ }^{28}$ These receptors changes may influence the physiological responses to a centrally active sedative medication, and thereby contribute to the development of tolerance to midazolam's sedative and respiratory depressant effects.

When administered to elderly patients receiving midazolam $\left(0.1 \pm 0.03 \mathrm{mg} \cdot \mathrm{kg}^{-1}, i v\right)$ for sedation during upper gastrointestinal endoscopic procedures, flumazenil reversed the residual sedative but not the ventilatory depressant effects of midazolam. ${ }^{29}$ In contrast, we found that flumazenil was effective in reversing some components of midazolam-induced ventilatory depression (e.g., the decrease in VT). Analogous to the finding of Gross et al.,$^{14}$ flumazenil did not reverse the depressant effects of midazolam on the $\mathrm{CO}_{2}$ response curve. However, Blouin et al. reported that following sedation with midazolam in the presence of a constant level of hypercarbia, reversal with flumazenil was associated with an increase in hypoxic ventilatory responsiveness. ${ }^{15}$ While flumazenil appears to have a transient beneficial effect in reversing benzodiazepine-induced respiratory depression, these changes may not be attributable solely to specific antagonistic effects of flumazenil at the respiratory centre. ${ }^{16}$ The mechanisms responsible for the respiratory changes following flumazenil administration ${ }^{14,15,18}$ may be influenced by other physiological factors which are known to increase central respiratory drive, in particular enhanced wakefulness. ${ }^{30}$

In conclusion, use of a midazolam infusion (0.3-0.5 $\mathrm{mg} \cdot \mathrm{min}^{-1}$ ) to achieve "deep" sedation during diagnostic procedures was not associated with clinically important ventilatory depression. The plasma midazolam concentrations at the end of the infusion period were similar to those previously reported to be associated with unconsciousness, suggesting that patients may develop tolerance to the sedative and respiratory depressant effects of midazolam during a one hour infusion. Finally, it would appear that flumazenil is more effective in reversing benzodiazepine-induced sedation than respiratory depression.

\section{Acknowledgment}

The authors would like to thank Ms. Joyce Mandujano for her assistance in the preparation of this manuscript.

\section{References}

1 Forster A, Gardaz J-P, Suter PM, Gemperle M. Respiratory depression by midazolam and diazepam. Anesthesiology 1980; 53: 494-7.

2 Bailey PL, Pace NL, Ashburn MA, Moll JWB, East KA, Stanley $T H$. Frequent hypoxemia and apnea after sedation with midazolam and fentanyl. Anesthesiology 1990; 73: 826-30.

3 Tucker MR, Ochs MW, White RP Jr. Arterial blood gas levels after midazolam or diazepam administered with or without fentanyl as an intravenous sedative for outpatient surgical procedures. J Oral Maxillofac Surg 1986; 44: 688-92.

4 Power SJ, Morgan M, Chakrabarti MK. Carbon dioxide response curves following midazolam and diazepam. $\mathrm{Br} \mathbf{J}$ Anaesth 1983; 57: 837-41.

5 Bailey PL, Andriano KP, Goldman M, Stanley TH, Pace $N L$. Variability of the respiratory response to diazepam. Anesthesiology 1986; 64: 460-5.

6 Berggren L, Eriksson I, Mollenholt P, Sunzel M. Changes in respiratory pattern after repeated doses of diazepam and midazolam in healthy subjects. Acta Anaesthesiol Scand 1987; 31: 667-72.

7 Alexander $C M$, Gross JB. Sedative doses of midazolam depress hypoxic ventilatory responses in humans. Anesth Analg 1988; 67: 377-82.

8 Mora CT, Torjman $M$, White PF. Effects of diazepam and flumazenil on sedation and hypoxic ventilatory response. Anesth Analg 1989; 68: 473-78.

9 Alexander $C M$, Teller $L E$, Gross $J B$. Slow injection does not prevent midazolam-induced ventilatory depression. Anesth Analg 1992; 74: 260-4.

10 Lauven PM, Schwilden H, Stoeckel H, Greenblatt DJ. The effects of benzodiazepine antagonist Ro 15-1788 in the presence of stable concentrations of midazolam. Anesthesiology 1985; 63: 61-4.

11 Brodgen $R N$, Goa $K L$. Flumazenil: a preliminary review of its benzodiazepine antagonist properties, intrinsic activity and therapeutic use. Drugs 1988; 35: 448-67.

12 White PF, Shafer A, Boyle WA III, Doze VA, Duncan S. Benzodiazepine antagonism does not provoke a stress response. Anesthesiology 1989; 70: 636-9.

13 Forster A, Crettenand G, Klopfenstein CE, Morel DR. Absence of agonist effects of high-dose flumazenil on ventilation and psychometric performance in human volunteers. Anesth Analg 1993; 77: 980-4.

14 Gross JB, Weller RS, Conard P. Flumazenil antagonism of midazolam-induced ventilatory depression. Anesthesiology 1991; 75: 179-85.

15 Blouin RT, Conard PF, Perreault S, Gross JB. The effect of flumazenil on midazolam-induced depression of the ventilatory response to hypoxia during isohypercarbia. Anesthesiology 1993; 78: 635-4l. 
16 Toriman $M$, Mora $C T$, White $P F$. Does flumazenil antagonize midazolam-induced depression of ventilatory response to hypoxia? (Letter). Anesthesiology 1994; 80: 233-4.

17 Mak KH, Wang YT, Cheong TH, Poh SC. The effect of oral midazolam and diazepam on respiration in normal subjects. Eur Respir J 1993; 6: 42-7.

18 Flögel $C M$, Ward DS, Wada DR, Ritter JW. The effects of large-doze flumazenil on midazolam-induced ventilatory depression. Anesth Analg 1993; 77: 1207-14.

19 Read DJC. A clinical method for assessing the ventilatory response to carbon dioxide. Australian Annals of Medicine 1967; 16: 20-32.

20 Rubio F, Miwa BJ, Garland WA. The determination of midazolam and two metabolites of midazolam in human plasma by gas chromatography-negative chemicalionization mass spectrometry. J Chromatogr 1982; 233 : 157-65.

21 Goldberg ME, Torjman M, Bartkowski RR, Mora CT, Boerner T, Seltzer $J L$. Time-course of respiratory depression after an alfentanil infusion-based anesthetic. Anesth Analg 1992; 75: 965-71.

22 Jones NL, Campbell EJM. Clinical Exercise Testing, 2nd ed. Philadelphia: W.B. Saunders Company 1982: 238-40.

23 Persson P, Nilsson A, Hartvig P, Tamsen A. Pharmacokinetics of midazolam in total iv anaesthesia. $\mathrm{Br} \mathrm{J}$ Anaesth 1987; 59: 548-56.

24 Sunzel M, Paalzow L, Berggren L, Eriksson I. Respiratory and cardiovascular effects in relation to plasma levels of midazolam and diazepam. Br J Clin Pharmacol 1988; 25: 561-9.

25 Tolksdorf W, Bremer H, Tokic B, van Laack MD, Meyers $W$. Respiratory depression after intravenous anesthesia is not related to vigilance. Anasthesie Intensivtherapie Notfallmedizin 1989; 24: 94-9.

26 Weinbrum A, Geller $E$. The respiratory effects of reversing midazolam sedation with flumazenil in the presence or absence of narcotics. Acta Anaesthesiol Scand 1990; 34: 65-9.

27 Takeda $R$, Haji A, Hukuhara T. Diazepam potentiates postsynaptic inhibition in bulbar respiratory neurons of cats. Respir Physiol 1989; 77: 173-86.

28 Skolnick P, Paul SM. Benzodiazepine receptors in the central nervous system. Int Rev Neurobiol 1982; 23: 103-40.

29 Caner AS, Bell GD, Coady T, Lee J, Morden A. Speed of reversal of midazolam-induced respiratory depression by flumazenil - a study in patients undergoing upper G.I. endoscopy. Acta Anaesthesiol Scand 1990; 34: 59-64.

30 Bellville JW, Howland WS, Seed IC, Houde RW. The effect of sleep on the respiratory response to carbon dioxide. Anesthesiology 1959; 20: 628-34. 